\title{
PERAMALAN DATA INDEKS HARGA KONSUMEN KOTA PURWOKERTO MENGGUNAKAN MODEL FUNGSI TRANSFER MULTI INPUT
}

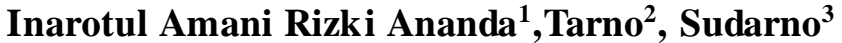 \\ 1,2,3 Departemen Statistika, Fakultas Sains dan Matematika, Universitas Diponegoro \\ Email: anandarizki673@yahoo.com
}

\begin{abstract}
The Consumer Price Index (CPI) provides information on changes in the average price of a group of fixed goods or services that are generally consumed by households within a certain period of time. The General CPI is formed from 7 sectors of public consumption expenditure groups. Because the formation of the consumer price index value is influenced by several sectors, the method that can be used is the transfer function method. The purpose of this study is to analyze the transfer function model so that the best model is produced to predict CPI in Purwokerto for the next several periods. In this study, general CPI modeling will be carried out based on the CPI value for the transportation services sector and the CPI for the Health sector in Purwokerto from January 2014 to July 2019 using the multi-input transfer function method. Based on the analys is, the best models are obtained, namely the multi-input transfer function model $(2,0,0)(0,1,0)$ and the ARIMA noise series ([3], 0,0). The model has an Akaike's Information Criterion (AIC) value of 72.42021 and an sMAPEvalue of $2,351591 \%$ which indicates that the model can be used for forecasting.
\end{abstract}

Keywords: Consumer Price Index(CPI), Inflation,transfer function, AIC

\section{PENDAHULUAN}

Tingkat inflasi merupakan rasio atau perbandingan perubahan indeks harga suatu periode terhadap indeks harga periode sebelumnya yang diukur berdasarkan indeks harga konsumen atau indeks harga lainnya. IHK memberikan informasi mengenai perkembangan rata-rata perubahan harga sekelompok tetap barang atau jasa yang pada umumnya dikonsumsi oleh rumah tangga dalam suatu kurun waktu tertentu. Terdapat 7 kelompok pengeluaran konsumsi masyarakat yang ikut andil dalam pembentukan IHK umum yaitu kelompok bahan makanan pokok, kelompok sandang, kelompok makanan jadi, minuman/rokok, kelompok perumahan, kelompok transportasi, kelompok kesehatan, kelompok rekreasi.

Besarnya pengaruh IHK terhadap laju inflasi ekonomi juga akan berdampak terhadap kemajuan perekonomian daerah. Maka diperlukan suatu model yang dapat digunakan untuk memprediksi nilai indeks harga konsumen sehingga dapat digunakan sebagai acuan dalam menentukan kebijakan di masa mendatang. Karena pembentukan nilai indeks harga konsumen dipengaruhi oleh beberapa sektor yang telah disebutkan sebelumnya, maka metode yang dapat digunakan adalah metode fungsi transfer. Dipilihnya metode fungsi transfer dalam meramalkan IHK karena model peramalan yang dibentuk melibatkan variabel prediktor dan respon yang berdasarkan deret waktu dan juga data IHK merupakan salah satu data time series.

Pada penelitian ini akan dilakukan pemodelan IHK dengan menggunakan metode fungsi transfer multi input dengan mengambil studi kasus di Kota Purwokerto yang didasarkan pada nilai IHK sektor jasa transportasi dan IHK sektor kesehatan. Permasalahan dalam penelitian ini adalah bagaimana prosedur pemode lan fungsi transfer untuk data IHK dengan studi kasus di kasus Purwokerto dari bulan Januari 2014-Juli 2019 untuk memperoleh model terbaik yang bisa digunakan untuk meramalkan IHK dan dari hasil peramalan itu bisa digunakan untuk mengukur tingkat inflasi di suatu daerah. 


\section{TINJAUANPUSTAKA}

\subsection{Indeks Harga Konsumen (IHK)}

Menurut Badan Pusat Statistik (2014), indeks harga konsumen (IHK) adalah indeks yang menghitung rata-rata perubahan harga dari suatu kelompok barang dan jasa yang dikonsumsi oleh rumah tangga dalam kurun waktu tertentu.

Perubahan IHK dari waktu ke waktu menggambarkan tingkat kenaikan harga (inflasi) atau tingkat penurunan harga (deflasi) dari barang dan jasa. Menurut BPS (2014), IHK dapat dihitung dengan metode Modified Laspayre.

$$
I_{n}=\frac{\sum_{i=1}^{k} \frac{P_{n i}}{P_{(n-1) i}}\left(P_{(n-1) i} . Q_{0 i}\right)}{\sum_{i=1}^{k} P_{0 i} \cdot Q_{0 i}} \times 100
$$

dengan:
$I_{n} \quad:$ Indeks bulan ke-n
$P_{n i} \quad$ : Harga jenis komoditi i pada bulan ke-n
$P_{(n-1) i} \quad$ : Harga jenis komoditi i pada bulan ke- $(\mathrm{n}-1)$
$P_{(n-1) i} Q_{0 i}:$ Nilai konsumsi jenis komoditi i pada bulan ke-(n-1)
$P_{0 i} \cdot Q_{0 i} \quad$ : Nilai konsumsi jenis komoditi i pada tahun dasar

\subsection{Analis is Deret Waktu (Time Series)}

Data deret waktu (time series) adalah data yang dikumpulkan, dicatat, atau diobservasi berdasarkan urutan waktu. Menurut Makridakis dkk. (1999), stasioneritas mempunyai makna bahwa tidak terdapat fluktuasi pada data. Kondisi stasioner terdiri atas dua hal yaitu stasioner dalam mean dan stasioner dalam varian.

Jika data time series tidak stasioner pada variannya, maka dapat dilakukan transformasi stabilisasi varian, seperti transformasi Box-Cox (Box-Cox power transformation) sebagai berikut (Wei, 2006)

$$
Z_{t}= \begin{cases}\frac{Z_{t}^{(\lambda)}-1}{\lambda}, & \lambda \neq 0 \\ \operatorname{Ln} Z_{t}, & \lambda=0\end{cases}
$$

Bila kondisi stasioner dalam rata-rata tidak terpenuhi diperlukan proses pembedaan (differencing). Secara umum apabila terdapat pembeda orde ke-d untuk mencapai stasioneritas dapat ditulis sebagai berikut:

$$
\nabla^{d} Z_{t}=(1-B)^{d} Z_{t}
$$

\subsection{Model Runtun Waktu}

Dalam pemodelan runtun waktu ARIMA, asumsi yang harus dipenuhi yaitu stasioneritas data dan $a_{t}$ adalah white noise. White noise berarti residual independen dan berdistribusi normal $N\left(0, \sigma_{a}^{2}\right)$. Menurut Soejoeti (1987), ada beberapa model time series yang dapat dituliskan sebagai berikut:

1. Proses Autoregressive (AR)

Bentuk umum proses Autoregresif tingkat $\mathrm{p}$ atau AR (p) adalah

$$
Z_{t}=\phi_{1} Z_{t-1}+\phi_{2} Z_{t-2}+\ldots+\phi_{p} Z_{t-p}+a_{t}
$$

2. Proses Moving Average (MA)

Bentuk umum proses Moving Averagetingkat q atau MA(q) adalah sebagai berikut:

$$
Z_{t}=a_{t}-\theta_{1} a_{t-1}-\theta_{2} a_{t-2}-\cdots-\theta_{q} a_{t-q}
$$


3. Proses Autoregressive Moving Average atau ARMA (p,q).

Bentuk umum proses ARMA $(\mathrm{p}, \mathrm{q})$ adalah sebagai berikut:

$$
Z_{t}=\phi_{1} Z_{t-1}+\phi_{2} Z_{t-2}+\ldots+\phi_{p} Z_{t-p}+a_{t}-\theta_{1} a_{t-1}-\theta_{2} a_{t-2}-\ldots-\theta_{q} a_{t-q}
$$

4. Proses Autoregressive Integrated Moving Average ARIMA $(p, d, q)$.

Bentuk umum dari proses ARIMA (p,d,q) adalah sebagai berikut:

$\phi_{p}(B)(1-B)^{d} Z_{t}=\theta_{q}(B) a_{t}$

\subsection{Fungsi Transfer}

Fungsi transfer merupakan metode pendekatan yang digunakan pada data deret waktu yang terhubung dengan satu atau lebih deret waktu lainnya (Makridakis, 1999). Tujuan pemodelan fungsi transfer adalah untuk menetapkan model sederhana yang menghubungkan deret output $\left(y_{t}\right)$ dengan deret input $\left(x_{t}\right)$ dan noise $\left(N_{t}\right)$ (Makridakis, 1999). Model fungsi transfer memiliki model umum sebagai berikut:

$$
y_{t}=\frac{\omega_{s}(B)}{\delta_{r}(B)} x_{t-b}+\frac{\theta(B)}{\phi(B)} a_{t}
$$

dengan

$\omega_{s}(B)=\left(\omega_{0}-\omega_{1} B-\omega_{2} B^{2}-\ldots-\omega_{s} B^{s}\right)$

$\delta_{r}(B)=\left(1-\delta_{1} B-\delta_{2} B^{2}-\ldots-\delta_{r} B^{r}\right)$

$\theta(B)=1-\theta_{1} B-\theta_{2} B^{2}-\ldots-\theta_{q} B^{q}$,

$\phi(B)=1-\phi_{1} B-\phi_{2} B^{2}-\cdots-\phi_{p} B^{p} B$

Pada fungsi transfer multi input atau multi input ada beberapa variabel input $X$ yang dimasukkan pada suatu pemodelan. Bentuk umum persamaan model fungsi transfer multi input adalah sebagai berikut : (Wei, 2005)

$$
y_{t}=\sum_{j=1}^{k} \frac{\omega_{j}(B)}{\delta_{j}(B)} B^{b j} x_{j t}+\frac{\theta(B)}{\phi(B)} a_{t}
$$

\subsection{Prosedur untuk Menentukan Model Fungsi Transfer Multi input}

Menurut Makridakis et al. (1999) tahap identifikasi model fungsi transfer adalah sebagai berikut:

\section{Mempersiapkan de ret input dan output}

Di dalam mempersiapkan pemodelan fungsi transfer, perlu mentransformasikan dan/atau membedakan deret-deret input dan output, terutama apabila terdapat ketidakstasioneran (Makridakis, 1999).

\section{Prewhitening (pemutihan) de ret input}

Pemutihan deret input bertujuan menjadikan deret input menjadi lebih dapat diatur dengan menghilangkan seluruh pola yang diketahui supaya yang tertinggal hanya white noise. Mengubah deret input $x_{t}$ menjadi deret $\alpha_{t}$ sebagai berikut:

$$
\frac{\phi_{X}(B)}{\theta_{x}(B)} x_{t}=\alpha_{t}
$$

\section{Prewhitening (pemutihan) de ret ouput}

Apabila suatu proses pemutihan diterapkan untuk $x_{t}$ maka proses yang sama juga harus diterapkan terhadap $y_{t}$ agar fungsi transfer dapat memetakan $x_{t}$ terhadap $y_{t}$. Berikut deret $y_{t}$ yang telah "diputihkan":

$$
\frac{\phi_{X}(B)}{\theta_{x}(B)} y_{t}=\beta_{t}
$$




\section{Perhitungan korelasi silang dan autokorelasi de ret input dan de ret output yang telah diputihkan}

Fungsi kore lasi silang a dalah ukuran kekuatan hubungan antar dua variabel. Korelasi silang antara $x$ dan $y$ menentukan tingkat hubungan antar nilai $x$ pada waktu t dengan nilai $y$ pada waktu $\mathrm{t}+\mathrm{k}$ (Makridakis,1999). Fungsi sampel cross correlation function ditulis sebagai berikut :

$$
\hat{\rho}_{x y}(k)=\frac{\hat{\gamma}_{X y}(k)}{\sigma_{x} \sigma_{y}}
$$

dengan $k=0, \pm 1, \pm 2, \pm, \ldots$,

$$
\begin{array}{r}
\hat{\gamma}_{x y}(k)= \begin{cases}\frac{1}{n} \sum_{t=1}^{n-k}\left(\mathrm{x}_{\mathrm{t}}-\overline{\mathrm{x}}\right)\left(\mathrm{y}_{\mathrm{t}+\mathrm{k}}-\overline{\mathrm{y}}\right), & k \geq 0 \\
\frac{1}{n} \sum_{t=1}^{n}\left(\mathrm{x}_{\mathrm{t}}-\overline{\mathrm{x}}\right)\left(\mathrm{y}_{\mathrm{t}+\mathrm{k}}-\overline{\mathrm{y}}\right), \quad k<0\end{cases} \\
S_{x}=\sqrt{\hat{\gamma}_{x x}(0)} \text { dan } S_{y}=\sqrt{\hat{\gamma}_{y y}(0)}
\end{array}
$$

\section{Penaksiran langsung bobot respon impuls}

Bobot respon impuls ini berguna untuk menghitung deret noise. Untuk penaksiran bobot respon impuls secara langsung rumusnya adalah sebagai berikut:

dengan

$$
v_{k}=\hat{\rho}_{\alpha \beta}(k) \frac{S_{\beta}}{S_{\alpha}}
$$

$\hat{\rho}_{\alpha \beta}(k)$ : nilai dari korelasi silang lag ke-k antar deret output dan input yang telah di prewhitening.

$S_{\beta} \quad:$ standar deviasi dari deret output yang telah diputihkan

$S_{\alpha} \quad$ : standar deviasi dari deret input yang telah diputihkan

\section{Penetapan $(r, s, b)$ untuk model fungsi transfer yang menghubungkan deret input dan de ret output}

Tiga parameter kunci dalam model fungsi transfer adalah $(\mathrm{r}, \mathrm{s}, \mathrm{b})$ dimana $\mathrm{r}$ menunjukkan orde fungsi $\delta(\mathrm{B})$, s menunjukkan orde fungsi $\omega(\mathrm{B})$ dan $\mathrm{b}$ menunjukkan keterlambatan yang dicatat pada $x_{t-b}$. Dibawah ini beberapa aturan yang digunakan untuk menduga nilai $\mathrm{r}$, s, b dari suatu fungsi transfer. (Wei,1994)

a. Nilai $\mathrm{b}$ menyatakan bahwa $y_{t}$ tidak dipengaruhi oleh $x_{t}$ sampai periode $\mathrm{t}+\mathrm{b}$. Besarnya $\mathrm{b}$ dapat ditentukan dari lag yang pertama kali signifikan pada pada plot korelasi silang.

b. Nilai s menyatakan seberapa lama deret $y_{t}$ terus dipengaruhi $x_{t-b-1}, x_{t-b-2}, \ldots, x_{t-b-s}$ sehingga dapat dikatakan bahwa nilai s adalah bilangan pada lag plot korelasi silang sebelum terjadinya pola menurun.

c. Nilai $r$ menyatakan bahwa $y_{t}$ dipengaruhi oleh nilai masa lalunya $y_{t-1}, y_{t-2}, \ldots, y_{t-r}$ $\mathrm{r}=0$ bila ada beberapa lag plot pada korelasi silang yang terpotong.

$\mathrm{r}=1$ bila plot pada korelasi silang menunjukkan suatu pola eksponensial menurun.

$\mathrm{r}=2$ bila plot pada kore lasi silang menunjukkan suatu pola eksponensial menurun dan pola sinus.

\section{Penaksiran awal deret gangguan $n_{t}$}

Bobot respon impuls dapat diukur secara langsung sehingga memungkinkan dilakukan perhitungan nilai taksiran dari deret gangguan $\mathrm{n}_{\mathrm{t}}$ dengan:

$$
\hat{n}_{t}=y_{t}-v_{0} x_{t}-v_{1} x_{t-1}-v_{2} x_{t-2}-\cdots-v_{g} x_{t-g}
$$




\section{Penetapan $\left(p_{n}, q_{n}\right)$ untuk model ARIMA $\left(p_{n}, 0, q_{n}\right)$ dari deret noise $\left(n_{t}\right)$}

Setelah didapat persamaan (52) maka nilai-nilai $n_{t}$ dimodelkan dengan pendekatan ARIMA sehingga diperoleh orde $p_{n}$ dan $q_{n}$ Model deret noise $n_{t}$ dapat dinyatakan dengan: $\phi_{n}(B) n_{t}=\theta_{n}(B) a_{t}$

9. Pengujian korelasi silang antara nilai sisa dengan deret gangguan yang telah diputihkan.

Bertujuan untuk memeriksa apakah residual (at) model fungsi transfer dan deret input yang telah diputihkan saling independen. Uji korelasi silang dapat menggunakan uji Ljung-Box dengan statistik uji:

$$
Q_{1}=m(m+2) \sum_{k=1}^{K}(m-k)^{-1} \hat{\rho}_{\alpha \alpha}(k)
$$

$\mathrm{H}_{0}$ ditolak jika $Q_{1} \geq \chi_{\alpha,(K+1)-M}^{2}$

10. Pengujian autokorelasi untuk nilai sisa model $(r, s, b)$ yang menghubungkan de ret input dan output

Bertujuan untuk melihat apakah terdapat korelasi antar residual (at) model fungsi transfer. Pengujian dilakukan melalui uji Ljung-Box dengan statistik uji:

$$
Q_{0}=m(m+2) \sum_{k=1}^{K}(m-k)^{-1} \hat{\rho}_{\alpha}(k)
$$

$\mathrm{H}_{0}$ ditolak jika nilai $Q_{0} \geq \chi_{\alpha, d f}^{2}$ atau $p$ value $<\alpha$.

\section{METODE PENELITIAN}

\subsection{Jenis dan Sumber Data}

Jenis data yang digunakan dalam penelitian ini adalah data sekunder yang diperoleh dari website BPS Kota Purwokerto. Deret output yang akan digunakan penelitian adalah data IHK Umum Kota Purwokerto dan deret input penelitian adalah data IHK di sektor transportasi dan kesehatan Kota Purwokerto dari bulan Januari 2014 sampai Juli 2019.

\subsection{Teknik Analisis Data}

Dari data dibagi menjadi dua yaitu data in sample untuk Januari 2014-Juli 2018 untuk pemodelan dan data out sampel Agustus 2019-Juli 2019 untuk evaluasi kinerja model dengan kriteria sMAPE Adapun tahapan-tahapan dalam pemodelan fungsi transfer multi input adalah sebagai berikut:

1. Tahap Identifikasi Model Fungsi Transfer

a. Mengidentifikasikan deret input dan output untuk mengetahui kestasioneran data dan menentukan orde model ARIMA.

b. Melakukan estimasi parameter model-model ARIMA yang sesuai untuk masingmasing deret input

c. Melakukan uji untuk mengetahui apakah model telah memenuhi syarat white noise atau belum

d. Memilih model ARIMA terbaik untuk deret input berdasarkan nilai AIC terkecil

e. Melakukan prewhitening terhadap model ARIMA dari deret input dan deret output.

f. Perhitungan korelasi silang untuk masing-masing deret input dan deret output yang telah diputihkan.

g. Penaksiran nilai bobot respon impuls untuk menghitung deret noise.

h. Menentukan nilai $\mathrm{r}, \mathrm{s}, \mathrm{b}$ pada masing-masing deret input

i. Penetapan $\left(p_{n}, q_{n}\right)$ untuk model ARIMA $\left(p_{n}, 0, q_{n}\right)$ dari deret noise $\left(n_{t}\right)$. 
j. Menetapkan model fungsi transfer multi input sementara.

$\mathrm{k}$. Penaksiran parameter fungsi transfer multi input dengan menggunakan metode conditional least square.

1. Melakukan uji signifikansi parameter-parameter model fungsi transfer

2. Pemeriksaan diagnostik model fungsi transfer multi input

3. Tahapan peramalan menggunakan model fungsi transfer multi input yang diperoleh.

\section{HASIL DAN PEMBAHASAN}

\subsection{Pengujian Stasioneritas Data}

Pada data masing masing deret input IHK sektor kesehatan dan IHK sektor transportasi secara visual dan uji Augmented Dickey-Fuller (ADF) tidak stasioner dalam mean sehingga dilakukan proses differencing 1 kali dan diperoleh nilai prob. masingmasing data yaitu 0,0000 sehingga dapat disimpulkan bahwa data setelah differencing 1 kali sudah stasioner dalam mean. Pada uji stasioneritas dalam varian dapat digunakan transformasi Box-Cox dan diperoleh nilai rounded value $(\lambda)$ data deret input adalah $\lambda=1$ yang dapat disimpulkan bahwa data setelah differencing 1 kali sudah stasioner dalam varian.

\subsection{Pemodelan ARIMA Deret Input}

Berikut ini tabel hasil kesimpulan dari pengujian signifikansi parameter, pengujian asumsi independensi residual, normalitas residual dan homogenitas varian residual (ARCH-LM), serta nilai AIC untuk masing-masing model ARIMA yang terbentuk berdasarkan plot ACF dan PACF dari deret input IHK kesehatan dan IHK transportasi.

Tabel 1.Penentuan Model ARIMA Terbaik Deret Input IHK Kesehatan Setelah Differencing

\begin{tabular}{cccccc}
\hline Model & $\begin{array}{c}\text { Signifikansi } \\
\text { Parameter }\end{array}$ & $\begin{array}{c}\text { Independensi } \\
\text { Residual }\end{array}$ & $\begin{array}{c}\text { Normalitas } \\
\text { Residual }\end{array}$ & \multirow{2}{*}{ ARCH-LM } & \multirow{2}{*}{ AIC } \\
\hline ARIMA ([2],1,0) & Signifikan & Independen & Ya & Terpenuhi & 22,7992 \\
ARIMA (0,1,[2]) & Signifikan & Tidak & Tidak & Terpenuhi & 37,9867 \\
ARIMA ([2],1,[2) & Signifikan & Independen & Ya & Terpenuhi & 18,9274 \\
\hline
\end{tabular}

Berdasarkan tabel 1 diketahui model yang memiliki AIC terkecil adalah model ARIMA ([2],1,[2]) maka model tersebut terpilih menjadi model terbaik dengan mode lnya yaitu :

$$
\begin{gathered}
\left(1-B-\phi_{2} B^{2}+\phi_{2} B^{3}\right) \mathrm{X}_{1, \mathrm{t}}=\left(1-\theta_{2} \mathrm{~B}^{2}\right) \alpha_{1, \mathrm{t}} \\
\left(1-B-0,95553 B^{2}+0,95553 B^{3}\right) \mathrm{X}_{1, \mathrm{t}}=\left(1-0,59356 \mathrm{~B}^{2}\right) \alpha_{1, \mathrm{t}}
\end{gathered}
$$

Tabel 2.Penentuan Model ARIMA Terbaik Deret Input IHK Transportasi Setelah Differencing

\begin{tabular}{cccccc}
\hline \multirow{2}{*}{ Model } & $\begin{array}{c}\text { Signifikansi } \\
\text { Parameter }\end{array}$ & $\begin{array}{c}\text { Independensi } \\
\text { Residual }\end{array}$ & $\begin{array}{c}\text { Normalitas } \\
\text { Residual }\end{array}$ & \multirow{2}{*}{ ARCH-LM } & \multirow{2}{*}{ AIC } \\
\hline ARIMA([2],1,0) & Signifikan & Independen & Ya & Terpenuhi & 245,057 \\
ARIMA $(0,1,[2])$ & Signifikan & Independen & Tidak & Terpenuhi & 245,975 \\
\hline
\end{tabular}

Berdasarkan tabel 2 diketahui model yang memiliki AIC terkecil adalah model ARIMA ([2],1,0) maka model tersebut terpilih menjadi model terbaik dengan modelnya yaitu :

$$
\begin{gathered}
\left(1-\phi_{2} B^{2}\right)(1-\mathrm{B}) \mathrm{X}_{2, \mathrm{t}}=\alpha_{2, \mathrm{t}} \\
\left(1-B-(-0,32981) B^{2}+(-0,32981) B^{3}\right) \mathrm{X}_{2, \mathrm{t}}=\alpha_{2, \mathrm{t}}
\end{gathered}
$$




$$
\left(1-B+0,32981 B^{2}-0,32981 B^{3}\right) \mathrm{X}_{2, \mathrm{t}}=\alpha_{2, \mathrm{t}}
$$

\subsection{Pe mutihan De ret Input dan Deret Output (Prewitening)}

Setelah didapatkan model ARIMA terbaik untuk masing-masing deret input, maka tahap pemutihan deret input dapat dilakukan.

1. Pemutihan deret input.

Model pemutihan deret input untuk IHK kesehatan dengan model ARIMA ([2],1,[2]) sebagai berikut:

$$
\frac{\left(X_{1, t}-X_{1, t-1}-0,95553 X_{1, t-2}+0,95553 X_{1, t-3}\right)}{\left(X_{1, t}-0,59356 X_{1, t-1}\right)}=\alpha_{1, t}
$$

Model pemutihan deret input untuk IHK transportasi dengan model ARIMA ([2],1,0) sebagai berikut:

$$
X_{2, t}-X_{2, t-1}+0,32981 X_{2, t-2}-0,32981 X_{2, t-3}=\alpha_{2, \mathrm{t}}
$$

2. Pemutihan deret output.

Model pemutihan deret output untuk IHK kesehatan dengan model ARIMA ([2],1,[2]) sebagai berikut:

$$
\frac{\left(Y_{t}-Y_{t-1}-0,95553 Y_{t-2}+0,95553 Y_{t-3}\right)}{\left(Y_{t}-0,59356 Y_{t-1}\right)}=\beta_{1, t}
$$

Pemutihan deret output untuk IHK transportasi dengan model ARIMA ([2],1,0) sebagai berikut:

$$
Y_{t}-Y_{t-1}+0,32981 Y_{t-2}-0,32981 Y_{t-3}=\beta_{2, t}
$$

\subsection{Pembentukan fungsi korelasi silang (Cross Correlation Function)}

Plot fungsi korelasi silang antara deret input dan deret output dapat dilihat pada gambar dibawah ini :

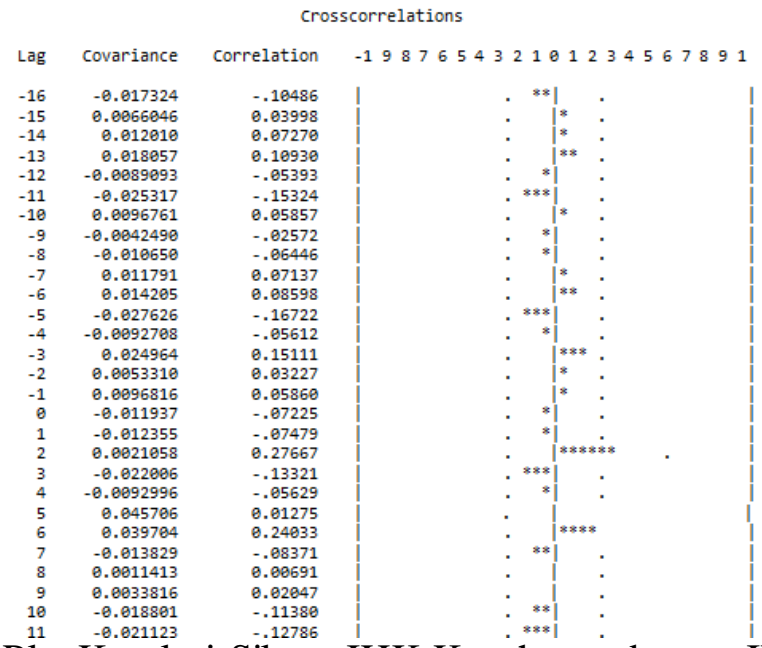

Gambar 1 Plot Korelasi Silang IHK Kesehatan dengan IHK Umum 


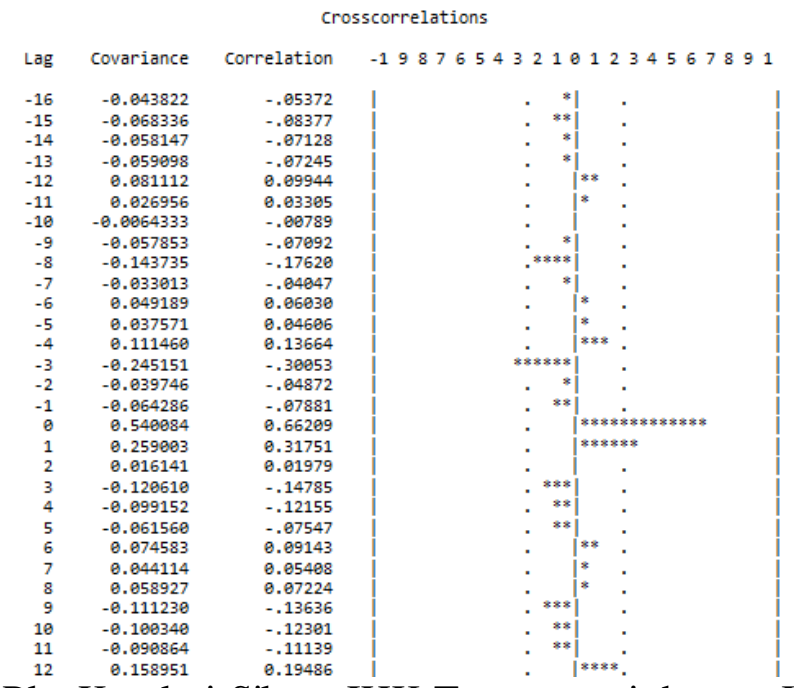

Gambar 2 Plot Korelasi Silang IHK Transportasi dengan IHK Umum

\subsection{Penetapan orde ( $r, s, b)$ untuk model fungsi transfer dan Penaksiran deret gangguan}

Penentuannya menggunakan grafik kore lasi silang yaitu dilihat dari lag yang pertama kali mempengaruhi y secara signifikan. Berikut merupakan perkiraan $(r, s, b)$ untuk model fungsi transfer:

Tabel 3 Estimasi Penentuan (r, s, b)

\begin{tabular}{cccc}
\hline Variabel Input & $\mathrm{b}$ & $\mathrm{s}$ & $\mathrm{r}$ \\
\hline IHK Kesehatan $\left(X_{1}\right)$ & 2 & 0 & 0 \\
IHK Transportasi $\left(X_{2}\right)$ & 0 & 1 & 0 \\
\hline
\end{tabular}

Berdasarkan nilai korelasi silang pada Gambar 1 dan 2 masing-masing deret input diketahui nilai $\mathrm{r}$ adalah nol karena lag-lag pada korelasi silang tidak menunjukkan pola yang jelas. Sementara untuk nilai $b$ dapat dilihat lag pertama yang mempengaruhi secara signifikan pada IHK kesehatan adalah lag 2 dan setelah itu tidak terdapat lag lain yang signifikan, maka dari itu nilai s adalah nol. Kemudian pada IHK transportasi lag pertama signifikan adalah lag ke 0 maka nilai b adalah nol, dan setelah lag ke- 0 terdapat lag yang signifikan yaitu lag ke-1 maka dari itu nilai s adalah 1 .

Setelah dilakukan uji asumsi yang memenuhi uji signifikan parameter, memenuhi asumsi autokorelasi residual, fungsi korelasi silang dengan nilai sisa model dengan deret input yang diputihkan tidak berkorelasi, berdistribusi normal, dan homoskedastisitas residual model yaitu $(2,0,0)(0,1,0)$ dengan model deret gangguan yaitu ARIMA ([3],0,0).:

Tabel 4 Uji Signifikansi Parameter Model Fungsi Transfer Multi Input

\begin{tabular}{ccccccc}
\hline Nilai (b,s,r) & $\begin{array}{c}\text { ARIMA } \\
\text { deret noise }\end{array}$ & Parameter & $\begin{array}{c}\text { Estimasi } \\
\text { Parameter }\end{array}$ & thitung & p-value & Keputusan \\
\hline$(2,0,0)(0,1,0)$ & $([3], 0,0)$ & $\phi_{1}$ & $-0,40209$ & $-3,24$ & 0,0020 & $\mathrm{H}_{0}$ ditolak \\
\cline { 3 - 6 } & & $\omega_{0}$ & 0,77339 & 6,97 & $<, 0001$ & $\mathrm{H}_{0}$ ditolak \\
\cline { 2 - 6 } & & $\omega_{0}$ & 0,20826 & 6,46 & 0,0013 & $\mathrm{H}_{0}$ ditolak \\
\cline { 2 - 6 } & & $\omega_{1}$ & $-0,10487$ & $-3,36$ & $<, 0001$ & $\mathrm{H}_{0}$ ditolak \\
\hline
\end{tabular}

Sehingga model fungsi transfer multi input sebagai berikut:

$$
\begin{aligned}
& y_{t}=\omega_{0}\left(x_{1}\right)_{\mathrm{t}-2}+\left(\omega_{0}-\omega_{1}\right)\left(x_{2}\right)_{\mathrm{t}}+\frac{1}{1-\phi_{1} \mathrm{~B}^{3}} a_{t} \\
& y_{t}=0,77339\left(x_{1}\right)_{\mathrm{t}-2}+(0,20826+0,10487)\left(x_{2}\right)_{\mathrm{t}}+\frac{1}{1+0,40209 \mathrm{~B}^{3}} a_{t}
\end{aligned}
$$




\subsection{Penggunaan Model Fungsi Transfer Multi Input untuk Peramalan}

Setelah didapatkan model fungsi transfer multi input yang telah menghasilkan parameter-parameter signifikan dan memenuhi asumsi maka model tersebut dapat digunakan untuk meramalkan IHK Umum di Kota Purwokerto beberapa periode kedepan. Berikut hasil peramalannya disajikan pada tabel 5.

Tabel 5 Hasil Peramalan Indeks Harga Konsumen Umum di kota Purwokerto

\begin{tabular}{ccccc}
\hline Periode & Peramalan & Batas Atas & Batas Bawah & Nilai Aktual \\
\hline Agustus 2019 & 134,5595 & 132,9481 & 136,171 &, \\
September 2019 & 134,7454 & 132,7531 & 136,7378 &, \\
Oktober 2019 & 134,9371 & 132,7512 & 137,123 &, \\
November 2019 & 135,2594 & 132,8456 & 137,6731 &, \\
Desember 2019 & 135,472 & 132,8407 & 138,1032 &, \\
Januari 2020 & 135,7662 & 132,8822 & 138,6501 &, \\
Febuari 2020 & 135,8822 & 132,7685 & 138,9958 &, \\
Maret 2020 & 136,1468 & 132,7855 & 139,5081 &, \\
April 2020 & 136,2728 & 132,6888 & 139,8568 &, \\
Mei 2020 & 136,5622 & 132,7374 & 140,3871 &, \\
Juni 2020 & 136,686 & 132,6348 & 140,7372 &, \\
Juli 2020 & 136,956 & 132,6568 & 141,2553 &, \\
Agustus 2020 & 137,0607 & 132,5269 & 141,5945 &, \\
\hline
\end{tabular}

Nilai sMAPE dari peramalan model fungsi transfer multi input berdasarkan data out sample ini sebesar 2,351591\% sehingga kemampuan peramalan dikatakan sangat baik karena nilai sMAPE yang diperoleh kecil. Maka model tersebut dapat digunakan untuk peramalan.

\section{KESIMPULAN}

Berdasarkan hasil dan pembahasan yang dilakukan pada bab sebelumnya, maka dapat diperoleh kesimpulan sebagai berikut:

1. Dari identifikasi model fungsi transfer diperoleh model fungsi transfer multi input dengan variabel input IHK sektor kesehatan dan IHK sektor transportasi terhadap IHK umum di Kota Purwokerto sebagai berikut :

$$
y_{t}=0,77339\left(x_{1}\right)_{\mathrm{t}-2}+(0,20826+0,10487)\left(x_{2}\right)_{\mathrm{t}}+\frac{1}{1+0,40209 \mathrm{~B}^{3}} a_{t}
$$

2. Model fungsi transfer multi input yang telah terbentuk memiliki sMape sebesar 2,351591\% sehingga kemampuan peramalan dikatakan sangat baik karena nilai sMAPE yang kurang dari $10 \%$. Maka model tersebut dapat digunakan untuk peramalan IHK di Kota Purwokerto.

\section{DAFTAR PUSTAKA}

Aswi dan Sukarna. 2006. Analisis Deret Waktu:Teori dan Aplikasi. Cetakan pertama (Suntingan: Arif Tiro, Muhammad). Makasar: Andira Publisher.

Bank Indonesia. Maret 2016. Indeks Harga Konsumen. Jakarta: Departemen Statistik.

Draper, N.R. dan Smith, H. 1992. Applied Regression Analysis Second Edition. New York: John Wiley and sons, Inc.

Falk, M., et al. 2006. A first course on time series analysis: examples with SAS. Jerman: University of Wurzburg.

Fathurahman, M. 2009. Pemodelan Fungsi Transfer Multi Input. Informatika Mulawarman: Jurnal Ilmiah Ilmu Komputer, Vol.4, No. 2: Hal 8-17. 
Render, B., dan Heizer, J. 2001. Prinsip-prinsip manajemen operasi. Jakarta: Salemba Empat.

Liu, L. M., \& Hanssens, D. M. 1982. Identification of multiple-input transfer function models. Communications in statistics-theory and methods, Vol.11, No. 3, Hal. 297314.

Makridakis, S., Wheelwright, S.C. dan Hyndman, R.J. 1999. Forcasting: Method and Aplication. New York: Wiley.

Ma'rufah, N.R., Rahayu, S.P., \& Suhartono. (2013). Peramalan pendapatan operasional bank menggunakan metode fungsi transfer dan neural network. Jurnal Sains dan Seni ITS, Vol.2, No. 2: Hal 219-224.

Rosadi, D. 2012. Ekonometrika dan Analisis Runtun Waktu Terapan dengan Eviews. Yogyakarta: ANDI.

Soejoeti, Z. 1987. Analisis Runtun Waktu. Jakarta: Universitas Terbuka.

Tsay, R. S. 2005. Analysis of financial time series: Financial Econometrics. New York: John Wiley and sons, Inc.

Wei, W. 2006. Time Series Analysis: Univariate and Multi inpute Methods, Second Edition. Boston: Pearson Education Inc. 